\title{
Ensino e Aprendizado de Phrasal Verbs: Alguns Insights a partir da Pesquisa com Leitura
}

\author{
Adriana Mesquita Rigueira
}

PUC-Rio

\begin{abstract}
O presente estudo enfoca um tipo de item lexical, o phrasal verb, que normalmente impõe dificuldades tanto para alunos quanto para professores de língua inglesa, devido aos seus aspectos semânticos e sintáticos. A pesquisa enfoca, mais particularmente, a compreensão dos phrasal verbs na leitura. Os dados coletados foram analisados à luz de uma fundamentação teórica de definição e classificação dos phrasal verbs, bem como de uma visão da leitura que valoriza a construção de sentido através de agrupamento de palavras (chunking).
\end{abstract}

Palavras-chaves: phrasal verb, item lexical, construção, sentido, leitura

\section{INTRODUÇÃO}

Nas últimas décadas, fomos testemunhas de uma revalorização do léxico no ensino e aprendizagem de língua inglesa, fato que tem se refletido não só no pensamento acadêmico, mas também na elaboração de materiais didáticos e na pedagogia dos professores.

A explicação para esse interesse renovado encontra-se, talvez, em publicações mais recentes (Nation, 2001; Schmitt \& McCarthy, 1997; Lewis, 1993, 1997, 2000), que apontam na direção de uma compreensão gradativa, segundo a qual, para que o aluno se expresse com relativa precisão e fluência, seja oralmente ou por escrito, ele necessita, dentre outros aspectos lingüísticos, de bom domínio de vocabulário. De fato, não é raro observarmos que as palavras "faltam", tanto na produção quanto na recepção, causando no aluno uma sensação de perda de memória ou incapacidade de recuperação do que foi aprendido.

É possível que os diferentes métodos de ensino estejam na origem das dificuldades apresentadas por nossos alunos - ou ao menos afetando seu aprendizado de vocabulário. No caso da abordagem de ensino de línguas mais contemporânea, a Abordagem Comunicativa, a valorização da fluência relegou a segundo plano a precisão no 
uso das palavras. O aluno era estimulado a se expressar livremente e negociar sentidos na interação, sem muita interferência do professor para corrigi-lo.

Mais particularmente no que diz respeito à compreensão na leitura, a Abordagem Comunicativa trouxe a necessidade de se ler pelo "significado", e não apenas pela estrutura do texto. Nesse sentido, o aluno deve contar com estratégias que incluem a possibilidade de acionar seu pré-conhecimento usando o "co-texto" e o "contexto", bem como a sua experiência de mundo e de outros textos, que o auxiliam na inferência dos significados das palavras desconhecidas. Entretanto, pode-se observar que os problemas de compreensão impostos por um texto ao aprendiz de língua inglesa não podem ser resolvidos unicamente com ênfase nessas estratégias. A esse respeito, Laufer afirma que “(...) tem-se demonstrado com freqüência que a compreensão da leitura está fortemente relacionada com o conhecimento de vocabulário, mais ainda que com os outros componentes da leitura"1 $(1997: 20)$.

Tem-se aí a confirmação de que o vocabulário desempenha um papel fundamental na construção de significados na leitura, devendo, portanto, receber um tratamento adequado, tanto da parte dos professores quanto de autores de livros didáticos.

$\mathrm{Na}$ esteira das dificuldades inerentes ao ensino/aprendizado de vocabulário na língua inglesa, arrastam-se expressões tipicamente idiomáticas. Como são freqüentemente portadoras de significados que vão além das palavras que as compõem, costumam ser um obstáculo para o aprendiz da língua. É o caso dos chamados phrasal verbs. Trata-se de itens lexicais - em inglês, lexical items, conforme Lewis (1993) - de inquestionável relevância para a proficiência em língua inglesa, mas que, por outro lado, tendem a gerar estranhamento ou confusão por suas características sintáticas e semânticas, amplamente discutidas na pesquisa que aqui apresentamos de forma resumida.

O objetivo de nossa pesquisa foi investigar a construção de significado pelo aluno de inglês ao se deparar com phrasal verbs possivelmente desconhecidos, já que são estruturas que existem em grande diversidade e aparecem com freqüência nos mais variados gêneros textuais. Acreditamos que uma investigação dessa natureza pode contribuir para a compreensão de como o processamento dos phrasal verbs é realizado pelos alunos de inglês como língua estrangeira, e de como o processamento da informação é por eles afetado. Acreditamos, ainda, que ela pode servir para atenuar de alguma maneira as barreiras que se interpõem à prática de sala de aula, no que diz respeito à apresentação e

\footnotetext{
${ }^{1}$ Todas as traduções de citações contidas neste artigo são de minha autoria.
} 
assimilação desses verbos.

\section{O ENSINO/APRENDIZADO DE PHRASAL VERBS}

\section{Os phrasal verbs como parte de uma categoria mais ampla: a dos idioms}

Poucas línguas não-germânicas conhecem estruturas como os phrasal verbs, pois trata-se de um fenômeno típico da língua inglesa e de algumas línguas cognatas, como o holandês. Naturalmente, para falantes de outras línguas, como o português, pode ser difícil não apenas entender um phrasal verb, mas também aceitá-lo como uma unidade de significado. A falta de equivalência entre a língua materna e a estrangeira gera frustração e, muitas vezes, cria barreiras ao aprendizado. Tem-se a impressão de que, à dificuldade já vivenciada pelo aluno com respeito ao uso das preposições em inglês, somam-se essas associações com verbos. Sem dúvida, a resistência por parte do aluno é indesejável e deve ser evitada, uma vez que o conhecimento dessas combinações verbais facilita muito o entendimento do inglês coloquial.

Primeiramente, é importante ressaltar que o phrasal verb é um tipo de "item lexical", noção fundamental para o ensino e aprendizado dessas estruturas. Partindo da Abordagem Lexical, Lewis (1993:89) se baseia em Pawley \& Syder (apud Richards, J. \& Schmidt, R., 1983) para fazer a seguinte caracterização dos itens lexicais: a) seu significado não é totalmente previsível a partir de sua forma; b) cada item constitui-se em unidade mínima para determinados fins lexicais; e, finalmente, c) cada qual é uma instituição social. Isso porque a língua é um fenômeno social; não se realiza individualmente, mas em contextos socialmente definidos (ibid., p.90). Na realidade, o phrasal verb está inserido na categoria das polipalavras (poliwords) e, segundo o autor, constitui o único tipo de item nessa categoria com destaque na língua inglesa. Porém, na categoria que considera a "mais desorganizada", existem outras polipalavras que merecem mais atenção. As preposições complexas, por exemplo (on account of, because of, due to) também são polipalavras usadas regularmente.

Já para Moon (1997), o phrasal verb constitui um item composto de múltiplos elementos (multi-word item). Trata-se de um item vocabular formado de uma seqüência de duas ou mais palavras. Essa seqüência constitui semântica e/ou sintaticamente uma unidade inseparável e com significado. Três critérios ajudam a identificar esses itens, considerados de forma holística: a) institucionalização (institutionalization), ou o grau de 
convenção do item na língua - por exemplo, ele é recorrente?; b) fixação (fixedness), ou o grau de cristalização adquirido pela seqüência de palavras - até que ponto esta pode ser flexionada?; e c) não-composicionalidade (non-compositionality), que indica o grau em que o item não pode ser interpretado palavra por palavra, mas pelo seu significado unitário e especializado. Os três critérios estão presentes em graus distintos em cada item lexical.

Dada a característica idiomática do phrasal verb, que leva inclusive o aprendiz de inglês a se referir aos mesmos como expressões, indagamo-nos sobre a relação existente entre phrasal verbs e idioms. Um estudo mais aprofundado nos possibilitou observar que alguns autores (Makkai, 1972; Strassler, 1982, apud Fernando, 1996) utilizam os seguintes critérios para caracterizar um idiom: 1) Composição (Compositeness), indicando que os idioms são expressões formadas por várias palavras (red herring, make up, smell a rat etc.); 2) Institucionalização (Institutionalization), significando que são expressões convencionalizadas; e 3) Opacidade Semântica (Semantic Opacity), pois o significado de um idiom não equivale à soma dos significados de seus componentes; ou seja, com freqüência, o significado de um idiom é não-literal. Portanto, na concepção desses lingüistas, phrasal verbs são tipos de idioms.

\section{Mas, o que são exatamente phrasal verbs?}

Vimos anteriormente a relação do phrasal verb com o idiom; como o primeiro se encaixa, para alguns lingüistas, na definição do segundo. Um exame minucioso de algumas obras de referência nos levou a definições bem semelhantes do que é um phrasal verb, porém com diferenças de nomenclatura.

Em The Grammar Book, Celce-Murcia e Larsen-Freeman definem o phrasal verb como um verbo seguido de partícula, que pode ser uma preposição, um advérbio ou uma combinação dos dois. O verbo e a partícula juntos funcionam como um único verbo, como em: I always get up (arise) at six (Eu sempre me levanto às 6.) (1983:265)

Já a Collins Cobuild English Grammar refere-se aos phrasal verbs como "um grupo especial de verbos" (1996:162), consistindo de duas ou três palavras, mas que na maior parte dos casos são formados de duas palavras (aqui, os autores não usam o termo partícula.)

Para Quirk e Greenbaum, na University Grammar of English, os phrasal verbs são uma combinação de verbo principal com uma ou mais partículas, formando um verbo composto de múltiplos elementos (multi-word verb). Os autores distinguem entre phrasal verbs (verbo + partícula), prepositional verbs (verbo + preposição) e phrasal-prepositional 
verbs (verbo + partícula + preposição) (1973:347-348). Embora não sejam explícitos quanto à função da partícula, fica subentendido que esta funciona como advérbio. Em cada uma dessas categorias, os verbos variam na medida em que preservam seus significados individuais; podem ser mais ou menos idiomáticos.

Em Swan, observamos uma nítida preferência pelo termo two-word verb (1995:287, 582), ao termo phrasal verb, talvez para não confundir o aluno, dado o caráter pedagógico de sua gramática. Contudo, ficamos sem saber ao certo de que se constitui um phrasal verb para o autor: se é fruto da associação de verbo mais partícula adverbial somente, como em Quirk e Greenbaum, ou se tanto faz o verbo se associar a uma partícula adverbial ou a uma preposição para ser considerado um phrasal verb.

Basicamente, entre os autores citados, existem diferenças de nomenclatura; por exemplo, a noção de partícula é variável. Por outro lado, um dado presente em todas as definições é a característica da idiomaticidade. Alguns lexicógrafos, inclusive, utilizam esse critério como único na distinção entre phrasal verbs e outras combinações verbais.

Courtney (1983), no Longman Dictionary of Phrasal Verbs, define-os assim: “Os phrasal verbs são combinações idiomáticas de verbo e advérbio, ou verbo e preposição (ou verbo com ambos, advérbio e preposição). Eles causam dificuldades para alunos de inglês devido ao seu significado e gramática."

Já Spears (1993), do NTC's Dictionary of Phrasal Verbs, é mais abrangente:

[phrasal verb] 1. é uma colocação de verbo + partícula, na qual o verbo rege uma partícula que parece preposição, mas funciona como advérbio; ex: put it down, roll along, stand up, call her up, call up your friend. A partícula pode ocorrer antes ou depois do objeto direto. (...) 2. é um termo genérico que abarca o prepositional verb, o phrasalprepositional verb, a construção descrita na acepção 1 e outras colocações de verbo + partícula, em que a partícula é um advérbio ou outra palavra com função.

Por fim, o Longman Phrasal Verbs Dictionary (2000) nos dá mais detalhes:

"Um phrasal verb é um verbo que consiste de duas ou três palavras. A maioria dos phrasal verbs consiste de duas palavras - a primeira palavra é um verbo e a segunda é uma partícula. A partícula é um advérbio ou uma preposição. (...) Existem também phrasal verbs de três palavras. (...) Um aspecto importante dos phrasal verbs é que eles são tipicamente idiomáticos. Portanto, o significado total de um phrasal verb não pode ser compreendido juntando-se simplesmente os significados de suas partes individuais."

\section{Aspectos sintáticos e semânticos dos phrasal verbs}

Três itens principais chamam a atenção quando o assunto é a dificuldade no 
ensino/aprendizado de phrasal verbs: 1) o tipo de combinação verbal (que varia segundo a função da partícula: advérbio ou preposição); 2) a transitividade do verbo; e 3) a nãocomposicionalidade.

Os dois primeiros itens dizem respeito aos aspectos sintáticos da combinação verbal, ou seja, a sintaxe que rege as partes que a compõem. É importante que o aluno tenha consciência da possibilidade de mobilidade interna dessas unidades de significado quando a partícula tem função de "advérbio", pois isso permite uma separação entre suas partes. Para isso, ele deverá ter um conhecimento básico do que é um phrasal verb e de como este funciona: 1) trata-se de uma combinação verbal de "verbo + partícula"; 2) funciona como verbo (portanto, como uma única palavra); 3) pode ser intransitivo ou transitivo; 4) se for transitivo, pode ou não ser separado da partícula pelo seu objeto; 5) se for separável e o objeto for pronominal, este vem entre o verbo e a partícula; 6) a combinação pode ter um significado idiomático (ou não-literal).

Outros detalhes concernentes à definição do phrasal verb podem ser revelados ao aluno com o tempo, gradativamente. Por exemplo, saber se a partícula é um advérbio ou uma preposição não nos parece relevante antes de um nível de proficiência da língua avançado, pois o aluno pode facilmente confundir as funções. Para a maioria dos alunos, inclusive, a partícula é sempre preposição. A própria denominação de partícula já parece ter sido adotada com um propósito. Vejamos o que Palmer tem a dizer a esse respeito:

O termo partícula tem sido usado para não se distinguir entre preposição e advérbio. Pois, embora seja possível decidir, em praticamente qualquer frase, se uma partícula é advérbio ou preposição, uma característica de muitas partículas, mas não todas, é que elas podem ter ambas as funções. (1988:217)

Esses são alguns aspectos sintáticos que consideramos merecedores de atenção, e que têm uma implicação na pedagogia do ensino de phrasal verbs. Passemos agora ao terceiro dos três itens mencionados no início desta seção - a não-composicionalidade -, relacionado aos aspectos semânticos.

O significado de um phrasal verb pode variar segundo as combinações nas quais o mesmo se apresenta. De acordo com Moon (1997), estas podem ser transparentes (transparent), como break off (partir; tirar pedaço) e write down (escrever); completivas (completive), como eat up (comer com avidez) e stretch out (alongar), onde a partícula age reforçando o grau da ação denotada pelo verbo; e, por fim, opacas (opaque), como nos casos de butter up (puxar o saco) e tick off (repreender; irritar). Já para Palmer (1988:517), a distinção é mais direta: o sentido transparente ou literal se opõe ao sentido 
opaco. Acreditamos ser essa opacidade de sentido que torna um phrasal verb idiomático e pode confundir o aluno.

A despeito de o autor não considerar o phrasal verb um tipo de idiom, como o faz Makkai (1972), o aspecto da idiomaticidade encontra-se fortemente presente em sua categorização, como vimos anteriormente. Ao que tudo indica, no ensino/aprendizado de phrasal verbs, a essência da dificuldade reside no fato de que a interpretação de uma unidade de sentido não se dá pela decodificação palavra por palavra de seus componentes.

Embora tenhamos abordado os aspectos sintáticos e semânticos separadamente, não há como negar sua indissociabilidade. Nessa perspectiva, Fernando (1996:11) tece comentário elogioso ao trabalho de Cowie et al. (1983), não apenas por seu estudo da semântica dos idioms, mas principalmente pela demonstração de como a gramática e o significado se complementam para criar idiomaticidade. Talvez seja por isso que, segundo Lewis (1993), um item lexical do tipo do phrasal verb receba tanta proeminência no ensino da língua inglesa - ele esconde traços aparentemente imperceptíveis ao aprendiz.

Falta, no entanto, um tratamento mais explícito desses verbos não apenas pelo professor, mas principalmente pelos autores do material que ele utiliza. Segundo Laufer, "a compreensão de como as palavras são internalizadas pode afetar as decisões de professores e autores de conteúdos programáticos com relação à apresentação, prática e teste de vocabulário" (1997b:153).

\section{A LEITURA COMO FIO CONDUTOR DA PESQUISA}

A presente pesquisa teve como objetivo verificar como se dá a construção de sentido em textos de língua inglesa que contêm phrasal verbs. Tínhamos a intenção de saber como esses verbos são compreendidos pelo aluno e como essa compreensão interfere no grau de eficiência da leitura que ele faz.

Os phrasal verbs constituem itens lexicais muito freqüentes no texto escrito em inglês. Contudo, sua carga semântica acentuada os torna problemáticos, pois as possibilidades de combinações são inúmeras, e os significados por elas gerados, incontáveis. Por outro lado, se o aluno for advertido de que o sentido de frases como $I$ can't get through with it (Não consigo acabar isso.) pode não ser tão óbvio quanto parece à primeira vista, sua atitude em relação a essas construções será mais cautelosa.

Dentre as importantes estratégias de leitura, a pesquisa contemplou as estratégias de inferência lexical. Assim, foram abordados: 1) o conhecimento prévio do leitor (ou 
background knowledge) - que inclui o conhecimento lingüístico e o conhecimento de outros textos, capacitando-o a antecipar o desenrolar da narrativa; 2) a inferência do léxico pelo contexto - incluindo-se aí o co-texto; e, por fim, 3) o uso da língua materna, uma estratégia amplamente utilizada pelo aprendiz.

\section{Os modos de processamento e interação textual}

A experiência da leitura proporciona ao aluno uma interatividade com o texto, na qual ele resgata e constrói significados. Através desse processo interativo, o conhecimento que traz consigo é automaticamente confrontado com as informações contidas no texto, às quais referimo-nos como insumo (input), e que devem ser compatíveis também com sua bagagem lingüística, para que sua interpretação do material textual seja satisfatória (Nuttall, 1996; Hoey, 2001). A teoria dos esquemas é evocada por Carrell \& Eisterhold para explicar o processo:

De acordo com a teoria dos esquemas, o processo de interpretação é guiado pelo princípio de que toda informação nova é mapeada em relação aos esquemas existentes, e que todos os aspectos de tais esquemas devem ser compatíveis com as novas informações. (1996:76)

Naturalmente, as autoras referem-se a um tipo de processamento, digamos, ideal das informações contidas num texto; sabemos que essa compatibilidade pode ser relativa.

De qualquer forma, o princípio acima descrito dá origem a dois modos básicos de processamento da informação que governam a interação: o ascendente (ou bottom-up) e o descendente (ou top-down). O primeiro é evocado pela informação contida no texto, o input com o qual depara o leitor, ao passo que o segundo entra em ação para resolver ambigüidades ou selecionar possíveis interpretações geradas pelos novos dados. Supõe-se que no processo de leitura ambos os modos ocorram simultaneamente.

\section{Contexto e co-texto}

Recorrer ao contexto para inferir significados de termos desconhecidos é uma estratégia que todo aprendiz precisa utilizar. Segundo Nagy, "a interpretação de uma palavra em um dado contexto é necessariamente mais específica que o significado armazenado no léxico mental" (1997:66). O autor ainda chama a atenção para os significados de um phrasal verb do tipo de take off (como remover, tirar), por exemplo, que podem ser totalmente atribuídos a fatores contextuais. Entretanto, o contexto depende do co-texto (ambiente lingüístico) para possibilitar uma construção de sentido eficaz. Desse modo, a proficiência lingüística exerce influência no bom desempenho do aluno em 
usar as pistas contextuais. Lewis (1993) também afirma que o co-texto sustenta e limita as escolhas, que são intrínsecas à criação de significado.

No caso dos phrasal verbs, ao recorrer somente ao co-texto, o aprendiz pode não lograr o resultado desejado, se levarmos em conta a composição da combinação. Entra aqui a noção de "palavra" que possui o aprendiz, pois o esforço de reconhecimento que fará dependerá de como o mesmo concebe as representações gráficas presentes no texto.

Sem dúvida, uma concepção de palavra com base na língua materna - no nosso caso, o português - pode prejudicar a compreensão do phrasal verb. Por exemplo, se o aluno reconhece separadamente o verbo e a(s) partícula(s) que o segue(m), para fins de um processo eficaz de leitura, sua tentativa é passível de falha, uma vez que seu mecanismo de inferência não deve ser ativado para uma só palavra, mas para duas ou três, que formam, juntas, o chamado "item lexical”. É a identificação desse item que está em jogo para que não haja distorção de sentidos no texto.

Além disso, se o aluno não souber que o que tem diante dos olhos é um phrasal verb, como costuma acontecer com freqüência mesmo nos estágios mais avançados do aprendizado, fará algo que devemos aos poucos estimulá-lo a evitar e que Eskey e Grabe (1996) condenam: a leitura palavra por palavra, uma estratégia que efetivamente destrói suas chances de compreensão de grande parte do texto. Ao contrário, a leitura deve ser feita no nível de um agrupamento de palavras, ou chunking, como afirmam os autores: "Esta é uma habilidade especialmente importante para a leitura em inglês, uma língua em que seqüências de palavras freqüentemente funcionam como itens lexicais individuais (in spite of, put up with)". (1996:233)

\section{METODOLOGIA DE PESQUISA}

Em nossa investigação, optamos pelo uso de uma metodologia qualitativa, uma vez que nosso principal interesse reside no processo de compreensão de phrasal verbs por parte dos alunos. Os dados foram obtidos a partir de questionários para alunos e da técnica de protocolo verbal em grupo. A seguir, apresentamos as fases da pesquisa e os instrumentos nela utilizados.

\section{Objetivos da pesquisa}

Com base no interesse da pesquisa em revelar possíveis dificuldades do aprendizado de phrasal verbs a partir de sua compreensão em textos de língua inglesa, o presente estudo envolveu duas fases de coleta de dados, separadas por um intervalo de dois 
meses. Cada fase contou com um questionário, algumas atividades pedagógicas e um protocolo verbal em grupo, realizado através do chamado evento social de leitura. Nosso intuito era obter um conjunto máximo de informações relevantes que respondessem às perguntas da pesquisa, a saber:

1) Os alunos percebem e identificam um phrasal verb no texto?

2) Que estratégias são utilizadas pelos alunos para compreender um phrasal verb?

3) Em que medida estes verbos ajudam ou atrapalham a compreensão dos textos?

Cabe ressaltar que estamos adotando a posição de Celce-Murcia e Larsen-Freeman (1983), segundo a qual os phrasal verbs compreendem tanto as combinações com advérbio quanto as combinações com preposição.

\section{Participantes}

Os participantes da pesquisa eram alunos do programa de línguas estrangeiras no qual a pesquisadora leciona, que está sediado em uma universidade federal, e é aberto ao público. Inicialmente, duas turmas foram selecionadas, uma de nível adiantado, outra de conversação (oferecida após o curso regular). A primeira continha dezoito alunos, e a segunda, seis. Embora a diferença de níveis possa sugerir uma diferença de proficiência, isso não se verificou na prática.

Logo na primeira fase da pesquisa, observamos que o processamento das informações era muito semelhante entre os grupos, e decidimos, para a segunda fase, manter apenas o grupo adiantado, mais numeroso e um pouco mais homogêneo, em termos de faixa etária e de proficiência no inglês.

\section{A primeira fase da pesquisa}

A primeira fase da pesquisa foi realizada em dois dias de aula consecutivos. No primeiro dia, os alunos receberam um questionário semi-aberto (Anexo 1), com perguntas gerais sobre vocabulário e leitura, e as responderam sem se identificar. Depois, participaram de atividades pedagógicas preparatórias para o protocolo verbal em grupo, realizado na aula seguinte. No total, 24 alunos responderam ao questionário. Essa sondagem inicial tinha por objetivo saber como os alunos viam esses dois aspectos do ensino da língua, que importância davam aos mesmos e que dificuldades tais aspectos apresentavam.

As informações obtidas no primeiro questionário serviram de ponto de partida para a pesquisa, e foram depois trianguladas com aquelas obtidas no primeiro protocolo verbal. 
Quanto às atividades pedagógicas, constituíram-se de textos que continham phrasal verbs. Basicamente, nossa intenção era observar como os alunos lidavam com essas estruturas. De forma um tanto ingênua, também achamos que eles pudessem usar algum dos phrasal verbs das leituras na discussão que realizaram posteriormente. Entretanto, durante a interação, não se fez uso dos phrasal verbs presentes no texto.

Uma vez encerrada a atividade, realizou-se o primeiro protocolo verbal. A modalidade de protocolo em grupo utilizada na pesquisa qualitativa é denominada por Bloome (1983) evento social de leitura. Neste, o processamento de compreensão dos significados é realizado à medida que os alunos constroem os significados do texto que lêem em voz alta (think aloud).

Para Bloome, a leitura deixa de ser vista apenas como um processo cognitivo, de decodificação de símbolos impressos para a obtenção de significado, e com enfoque na relação escritor-leitor, para se tornar um processo social, em que o enfoque está na relação entre as pessoas envolvidas num evento de leitura.

Para o protocolo verbal 1 , o tipo de texto selecionado foi sinopse de filme. Os filmes veiculados pelas sinopses em questão eram exibidos nos vôos domésticos e internacionais da Varig: "Clockstoppers", “On the Line”, “Ocean’s Eleven”, "Hardball” e “John Q". As sinopses apareceram na sessão Cine Varig da revista Ícaro, revista de bordo da empresa, publicada em edição bilíngüe.

As cinco sinopses usadas no evento social de leitura foram selecionadas porque continham exemplos de combinações verbais (verbo + advérbio e verbo + preposição). Eram dez, no total: wind up, bring together, pull through, bet on, pay off, roll out, thrust into, steal over, run out e face off. Interessava-nos saber como o aluno-leitor depreendia o significado da combinação: primeiro, se percebia a estrutura como uma unidade de significado ou se tentava analisar as suas partes, contrariando o aspecto da nãocomposicionalidade, de Moon (1997) e segundo, se tinha noção do espectro de idiomaticidade de que fala Lewis (1993), que pode acarretar dificuldade na construção de sentido pelo leitor. No entanto, os alunos não estavam cientes de que nosso interesse residia nos phrasal verbs.

As sinopses 2 e 3 abaixo contêm as seguintes combinações: bring together e pull through, e bet on, pay off e thrust into, respectivamente. 


\section{S2 On the Line}

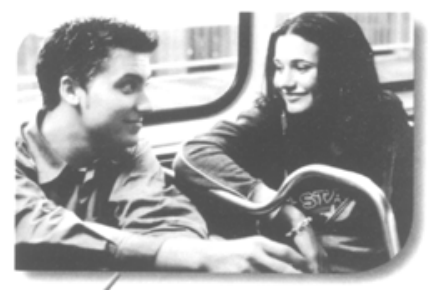

S3 Hardball

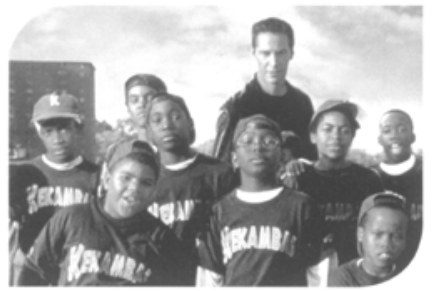

Kevin just met the girl of his dreams. But there's only one problem: he forgot to get her name and number. Now he and his friends will do anything to find her. And so Kevin becomes Chicago's poster boy for lost love. But do the forces of fate that brought them together in the beginning pull through a second time?

A ordem em que as sinopses foram apresentadas aos alunos na ocasião do protocolo verbal refletiu uma gradação em termos de complexidade de conteúdo, que levou em conta o vocabulário total de cada texto. Também cuidamos para que as combinações verbais representassem algum desafio para os nossos alunos.

O primeiro evento social de leitura, que constituiu nossa base de dados, reuniu os alunos de cada uma das turmas selecionadas em grupos de três e quatro. Ao todo, dezesseis alunos participaram desse evento. Nenhum critério específico foi utilizado, a não ser a disposição espacial da turma no dia: os alunos sentados à frente constituíram os sujeitos da pesquisa.

Após leitura e cuidadosa reflexão, os alunos comentaram a sinopse que leram, trocando idéias com os colegas do grupo, em português. O objetivo dessa atividade era observar o processo de construção de sentido pelos alunos: em que medida os phrasal verbs presentes constituíam uma barreira à depreensão de significado, e quais estratégias e recursos eles utilizavam para construir os significados de um texto com esse tipo de estrutura. Naturalmente, para o processamento desse tipo de informação, era necessário que o aluno identificasse os phrasal verbs.

\section{A segunda fase da pesquisa}

O segundo questionário - que se assemelha mais a uma "atividade" - foi aplicado dois meses depois, na primeira turma apenas, e contou com doze alunos; todos eles se identificaram. O questionário (Anexo 2) tomou como base três das cinco sinopses de filmes selecionadas anteriormente, e abordou as combinações verbais nelas contidas. Escolhemos para essa atividade as sinopses dos seguintes filmes: "On the Line" (S2), 
"Hardball" (S3) e "John Q" (S5).

Ao contrário do Questionário 1, em que as perguntas eram mais gerais, o que chamamos Questionário 2 foi, na realidade, uma atividade bem objetiva, que visou chamar a atenção do aluno para o phrasal verb. As questões foram as seguintes:

1) As sinopses abaixo contêm exemplos de phrasal verbs. Identifique-os, sublinhando-os;

2) Por que você acha que são phrasal verbs?;

3) Escreva abaixo o significado dos phrasal verbs que você sublinhou;

4) Destaque alguns phrasal verbs e diga por que você acha que eles têm esse significado.

As questões tinham por finalidade: a) verificar como os alunos entendem o que é um phrasal verb, informação que se evidencia na identificação das combinações nos textos e na conseguinte explicação do termo; b) investigar como eles interpretam um phrasal verb, ou seja, se o interpretam como uma unidade única de sentido ou como uma construção analisável; e, finalmente, c) observar como se dá o processamento dos phrasal verbs pelos alunos; em outras palavras, que estratégias utilizam na leitura para chegar àquele significado.

As respostas dadas a este questionário foram de fundamental importância para a pesquisa, pois serviram de ponte entre o primeiro e o segundo protocolos verbais, fornecendo-nos dados relevantes que foram triangulados na fase da análise.

$\mathrm{Na}$ aula que se seguiu à aplicação do questionário, foi implementada uma atividade pedagógica preparatória para o segundo evento social de leitura, que seria realizado na semana seguinte: os alunos foram expostos a alguns pares de combinações verbais, mostrados no retroprojetor. O objetivo era fazer com que os alunos distinguissem entre sentido literal e idiomático nas combinações. Ao todo, foram sete pares, dos quais quatro com combinações retiradas das sinopses. Por exemplo: He saw the mouse and ran out. (literalmente, Ele viu o gato e fugiu.) e Oil will run out in the next century. (Faltará petróleo no próximo século.)

Depois de muito discutirem sobre o que era literal e o que era idiomático, percebemos que os alunos não demonstravam segurança em relação ao que considerar um phrasal verb. Contudo, a tendência foi privilegiar a relação phrasal verb-idiomaticidade. Foi-lhes explicado, então, que, para alguns autores, de fato, só é considerada phrasal verb aquela combinação cujo sentido não pode ser depreendido de suas partes, ou seja, com sentido idiomático. Porém, outros autores consideram phrasal verbs toda e qualquer 
combinação verbal seguida de uma partícula (adverbial ou preposicional), e cujo significado seja literal ou idiomático.

Para o segundo evento social de leitura, também foram selecionados textos autênticos. O primeiro foi uma sinopse do filme "Serendipity" ("Escrito nas Estrelas"), impressa na embalagem do vídeo; já o segundo foi retirado da revista americana Time, publicado na seção Time Global Adviser, que anuncia artigos e presentes de Natal. Cada texto continha quatro casos de phrasal verbs. São eles: draw together, give up, keep apart e fall for no primeiro, e stand out, think up, fork out e hang out, no segundo.

O segundo evento social de leitura diferenciou-se do primeiro em alguns aspectos. Além de reduzirmos o número de participantes (no total, nove alunos foram gravados), o procedimento para a leitura também foi em parte modificado. A sinopse foi utilizada com um grupo, ao passo que o texto da Time foi utilizado com os outros dois grupos. Desta vez, os alunos foram advertidos para o fato de que os textos continham esses verbos, devendo, portanto, atentar para os mesmos.

\section{DISCUSSÃO DOS RESULTADOS}

Os dados coletados foram analisados considerando-se uma categoria geral, a saber, estratégias de inferência lexical, que subdividimos em dois eixos principais: o recurso da tradução e o uso do contexto/co-texto pelo aprendiz de língua inglesa.

Sustentamos nossa análise à luz das posições teóricas de vários estudiosos citados anteriormente, e acreditamos que tais teorias foram bastante elucidativas na compreensão das atitudes e respostas dos alunos observadas nas duas fases da pesquisa.

\section{Do recurso da tradução: a importância da língua materna}

A noção de item lexical, fundamental à retomada dos interesses pela aquisição de vocabulário em língua inglesa, compreende itens dos mais diversos tipos, como vimos com Lewis (1993) e Moon (1997). Entre esses itens, encontram-se os phrasal verbs.

A questão dos significados gerados por combinações verbais diversas - que vão de transparentes a opacas, segundo classificação de Moon (1997) e Palmer (1988) - é o que mais intriga profissionais da língua e do ensino. O aprendiz recorre, invariavelmente, à língua materna para entender significados isolados, que confundem mais do que auxiliam na compreensão de tais combinações.

$\mathrm{Na}$ análise dos protocolos e do questionário, constatamos que a língua materna é 
sempre acionada na construção de sentido, seja esta mais literal ou mais global. Assim, testemunhamos: 1) a tradução literal de combinações mais simples, como pay off, bet on, face off e think up, em que a presença da partícula parece não influir tanto no sentido, construído a partir do significado puro do verbo; 2) também se usou tradução literal das partes em combinações mais opacas, do tipo thrust into, bring together e fork out, na tentativa de se chegar ao sentido adequado; por fim, 3) já outras combinações de semelhante opacidade, como wind up, pull through e draw together, receberam interpretações mais globais.

No caso das combinações em 3 , observamos uma tradução de blocos de significado (chunks) que nos pareceu mais bem-sucedida que a tradução das partes realizada com o grupo de combinações em 2. De fato, segundo Lewis (1997), a tradução de chunks é mais eficaz que a tradução de palavras.

Pode-se dizer que, ao mesmo tempo em que a tradução constitui um recurso natural do aprendiz de língua inglesa, ela se revela também uma arma perigosa, caso ele não perceba que os sentidos literais por ela gerados podem ser inadequados. De qualquer modo, a análise dos dados revelou que, na medida do possível, o aluno tenta primeiro o sentido literal antes de chegar ao sentido mais global; trata-se de um ato involuntário.

Também pareceu-nos que, para compreender uma combinação verbal, seja ela phrasal verb ou não, o aluno age da seguinte maneira: inicialmente, tenta o significado do verbo sozinho, sem a partícula (caso de bet, pay, face e think). Quando não consegue entender o que lê com base apenas nesse significado, recorre ao significado também da partícula, juntando ambos (caso de thrust, bring e fork). Finalmente, na eventualidade de um verbo desconhecido, como parece ser o caso de wind, pull e draw, o aluno deixa o nível das palavras e passa para o nível das idéias, privilegiando assim o conteúdo em detrimento da forma. É aí que o papel do contexto/co-texto parece ser mais contundente.

\section{Do uso do contexto/co-texto}

Para o aluno-leitor de língua estrangeira, as pistas textuais são fundamentais quando se trata da busca de significados de termos desconhecidos. No caso dos phrasal verbs, o aluno muitas vezes necessita dessas pistas para entender o significado da combinação, uma vez que boa parte das combinações possui sentido idiomático. E quanto mais se souber a respeito do que está em volta da combinação, maiores são as chances de a leitura ser eficaz. De acordo com Nagy, "para inferir o significado de qualquer palavra vista em contexto, é útil conhecer os significados das palavras em torno dela” (1997:79). 
Em nossa análise, um exemplo patente de uso eficaz de pistas textuais está evidenciado na interpretação de pull through, que se apóia nos limites impostos pelas expressões de tempo que o cercam (at the beginning e a second time), bem como na outra combinação verbal que o antecede, bring together. Lewis também defende o co-texto como fator importante para sustentar e limitar as escolhas, intrínsecas à criação de significado: "Se o contexto é visto como situação + co-texto, é este último - linguagem co-ocorrente que é mais importante para a aprendizagem da língua" (1993:103).

Ao contrário do exemplo anterior, observamos também uso ineficaz de pistas textuais, como na tentativa de construção de sentido para a combinação thrust into. Notouse que, além da opacidade de sentido que caracteriza a combinação verbal, houve uma confusão com outro verbo do inglês, trust, mais conhecido. O co-texto aqui não ajudou, pois o termo molding não é de fácil entendimento, além de estar inserido em uma frase com outros termos aparentemente desconhecidos (all of a sudden e toughest), como ficou evidenciado nos protocolos. A ausência de pistas contextuais é igualmente visível no trecho que contém a combinação fork out, no protocolo verbal 2.

Finalmente, verificamos que, em alguns casos, o contexto e o co-texto pareceram ser mais importantes na depreensão do significado de outros termos e sintagmas que propriamente do phrasal verb, embora não possamos afirmar isso. O que se pode notar é que, nesses casos, o phrasal verb não foi muito problematizado na construção de sentido.

Dadas as nuances observadas na interpretação de phrasal verbs e construção de sentido de textos nos quais estes estavam inseridos, não se podem oferecer conclusões definitivas às nossas indagações iniciais. No entanto, as considerações feitas acima nos permitem oferecer insights, ainda que tentativamente, às perguntas da pesquisa.Vejamos:

\section{1) Os alunos percebem e identificam um phrasal verb no texto?}

No que concerne à composição do phrasal verb, os alunos demonstraram não conhecer muito bem sua estrutura, ao identificarem take care e stand-off, no questionário 2, como phrasal verb. Esses dois exemplos foram recorrentes nas respostas coletadas.

Quanto ao sentido, a análise de dados no protocolo verbal 1 nos revelou que os alunos, ao se referirem a combinações verbais, preferiram o termo "expressão" ao termo phrasal verb; já no protocolo verbal 2, como o objetivo era a identificação de phrasal verbs especificamente, o termo foi utilizado.

Ficou claro para nós que a idiomaticidade é uma característica forte do phrasal verb no imaginário do aprendiz de língua inglesa, e a identificação da combinação como 
phrasal verb parece depender muito da percepção dessa característica.

2) Que estratégias são utilizadas pelos alunos para compreender um phrasal verb?

A língua materna foi uma ferramenta indispensável para se chegar ao significado dos phrasal verbs, embora a tradução literal nem sempre tenha sido o melhor caminho (mas é, indubitavelmente, um recurso marcante em língua estrangeira).

Da mesma forma, podemos afirmar que tanto o co-texto quanto o contexto foram utilizados na interpretação, revelando-se mutuamente dependentes.

Por fim, não podemos nos esquecer do seu conhecimento de mundo, que faz com que seus esquemas de conhecimento entrem em ação e os significados do texto aflorem com mais facilidade. As situações descritas nas sinopses, por exemplo, remeteram os alunos a outras situações já vistas ou vividas por eles que, se não ajudaram, pelo menos prepararam os alunos para a interpretação dos textos, facilitando a compreensão dos phrasal verbs.

\section{3) Em que medida esses verbos auxiliam/atrapalham sua compreensão dos textos?}

Com exceção de thrust into, cuja interpretação não se mostrou tão eficaz, pode-se afirmar que, em muitos casos, não foram os phrasal verbs propriamente ditos que causaram ruptura no fluxo de processamento da informação no texto, mas sim outros termos nos quais os alunos acabaram detendo-se por mais tempo.

Podemos afirmar que os phrasal verbs ora auxiliam, ora atrapalham a construção de sentidos do texto na medida em que o verbo da combinação é mais ou menos conhecido do leitor. Se for conhecido, a tendência é que a interpretação se faça, primeiro, através da análise dos seus componentes; caso seja desconhecido, a interpretação tende a ser realizada de maneira mais global. Contudo, nossa investigação revelou que a construção de sentido é mais eficaz se os termos vizinhos forem também de conhecimento do leitor.

\section{CONCLUSÃO}

Ao introduzirmos este trabalho, enfatizamos a importância do vocabulário para o ensino/aprendizado de língua inglesa. Mencionamos que pesquisas mais recentes passaram a conferir às palavras um valor antes negligenciado por estudiosos e profissionais do ensino, estes comumente subordinados aos métodos vigentes em cada época. Sabe-se hoje - graças, inclusive, à Abordagem Lexical - que, sem o conhecimento de um vocabulário 
básico, o desempenho do aprendiz de inglês fica seriamente prejudicado.

Optamos por investigar o phrasal verb por nos parecer um tipo de item lexical de difícil compreensão e abordagem pedagógica no ensino de inglês como língua estrangeira. A análise de dados revelou que, mesmo após alguns anos de estudo, o aluno ainda encontra dificuldade em identificar um phrasal verb no texto, dificuldade que se deve a sua composição e sentido.

A leitura nos pareceu ser a habilidade lingüística mais adequada à observação da compreensão do phrasal verb pelo aluno, assim como a modalidade de protocolo em grupo conhecida como evento social de leitura nos pareceu ser uma maneira eficaz de coletar nossos dados, pois reflete, através da verbalização dos processos, o que se passa na mente do aluno. Além disso, a co-construção de sentidos assim realizada proporcionou aos sujeitos da pesquisa a oportunidade de compartilhar idéias e emoções que auxiliaram na determinação dos significados do texto.

Contribuíram também para a construção de sentidos as estratégias de leitura, cujo uso ficou evidenciado tanto na interpretação dos phrasal verbs registrada nos protocolos, quanto nas justificativas fornecidas no segundo questionário.

Após a análise dos dados, o que podemos dizer é que a informação lingüística referente aos phrasal verbs, conforme apresentada na revisão da literatura, parece ainda estar um pouco distante da realidade da sala de aula. O próprio material didático não reflete a complexidade que caracteriza o ensino/aprendizado dos phrasal verbs. Portanto, saber como apresentar o phrasal verb de forma "palatável" aos nossos alunos é uma tarefa que exige reflexão e paciência.

Por fim, não devemos esquecer que a materialidade lingüística estabelecida pelas palavras/expressões que compõem um texto precisa ser levada em conta na aprendizagem de língua estrangeira. Para se chegar ao sentido, é preciso passar pelo vocabulário. Por isso é que o vocabulário é tão importante e deve ser valorizado, também, pelos livros didáticos. E, como parte do vocabulário, os phrasal verbs.

\section{REFERÊNCIAS}

Bloome, D. (1983). Reading as a social process. In: Advances in reading/language research $\underline{165-}$ 195. Vol. 2. Greenwich: JAI Press. 
Carrell, P. L. \& Eisterhold, J. C. (1996). Schema theory and ESL reading pedagogy. In: P.L. Carrell, J. Devine, \& D. Eskey (eds.) Interactive approaches to second language reading 73-92. New York: Cambridge University Press.

Celce-Murcia, M. \& Larsen-Freeman, D. (1983). The grammar book: An ESL / EFL teacher's course. Rowley: Newbury House.

Coady, J. \& Huckin, T. (eds.) (1997). Second language vocabulary acquisition. Cambridge: Cambridge University Press.

Courtney, R. (1983). Longman dictionary of phrasal verbs. Harlow: Longman.

Cowie, A. P., Mackin, R. \& McCaig, I. R. (1983). Oxford dictionary of current idiomatic English. Vol.2. Oxford: Oxford University Press.

Eskey, D. E. \& Grabe, W. (1996). Interactive models for second language reading. In: P. L. Carrell, J. Devine, \& D. Eskey (eds.) Interactive approaches to second language reading 223238. New York: Cambridge University Press.

Fernando, C. (1996). Idioms and idiomaticity. Oxford: Oxford University Press.

Hoey, M. (2001). Textual interaction. New York: Routledge.

Laufer, B. (1997a). The lexical plight in second language reading: Words you know, words you don't know and words you can guess. In: J. Coady \& T. Huckin (eds.) Second language vocabulary acquisition 20-34. Cambridge: Cambridge University Press.

(1997b). What's in a word that makes it hard or easy: Some intralexical factors that affect the learning of words. In: N. Schmitt \& M. McCarthy (eds.) Vocabulary: Description, acquisition and pedagogy 140-155. Cambridge: Cambridge University Press.

Lewis, M. (1993). The lexical approach: The state of ELT and a way forward. Hove: LTP. (1997). Implementing the lexical approach: Putting theory into practice. Hove: LTP. (2000). Teaching collocation: Further developments in the lexical approach. Thomson Learning.

Longman phrasal verbs dictionary (2000). Harlow: Pearson Education.

Makkai, A. (1972). Idiom structure in English. The Hague: Mouton. 
Moon, R. (1997). Vocabulary connections: Multi-word items in English. In N. Schmitt \& M. McCarthy (eds.) Vocabulary: Description, acquisition and pedagogy 40-63. Cambridge: Cambridge University Press.

Nagy, W. (1997). On the role of context in first- and second-language vocabulary learning. In N. Schmitt \& M. McCarthy (eds.) Vocabulary: Description, acquisition and pedagogy 64-83. Cambridge: Cambridge University Press.

Nation, P. (2001). Learning vocabulary in another language. Cambridge: Cambridge University Press.

Nuttall, C. (1996). Teaching reading skills in a foreign language. London: Heinemann.

Palmer, F. R. (1988). The English verb. 2nd. ed. London: Longman.

Quirk, R. \& Greenbaum, S. (1973). A university grammar of English. London: Longman.

Richards, J. \& Schmidt, R. (1983). Language and communication. London: Longman.

Schmitt, N. \& McCarthy, M. (eds.) (1997). Vocabulary: Description, acquisition and pedagogy. Cambridge: Cambridge University Press.

Spears, R. A. (1993). NTC's Dictionary of phrasal verbs and other idiomatic verbal phrases. Chicago: National Textbook Company.

Strässler, J. (1982). Idioms in English: A pragmatic analysis. Tubingen: Verlag.

Swan, M. (1995). Practical English usage. 2nd. ed. Oxford: Oxford University Press. 


\section{ANEXO 1}

\section{Questionário 1}

1 - Dentro do seu nível de aprendizado, como você classificaria o seu vocabulário?
( ) Muito bom
( ) Bom
( ) Regular
( ) Ruim

2 - Você acha que as atividades abaixo o ajudam a aumentar seu conhecimento de vocabulário? (Numere-as por ordem de importância.)

( ) Usar a Internet

( ) Ler livros e revistas estrangeiras

( ) Escutar músicas e tentar traduzi-las

( ) Assistir a filmes procurando não ler as legendas

( ) Escutar fitas com narrativas e diálogos autênticos

3 - Na sua opinião, o que significa "aprender" vocabulário?

( ) Ser capaz de identificar o sentido das palavras ao ler um texto/ escutar gravações

( ) Conseguir empregá-las ao escrever um texto/ discorrer sobre determinado assunto

( ) Outro:

4 - Que estratégias utiliza para compreender o significado das palavras desconhecidas de um texto?

5 - Que procedimentos você adota para assimilar o vocabulário novo?

6 - Gostaria de acrescentar algum comentário? 


\section{ANEXO 2}

\section{Questionário/Atividade $-2^{\mathrm{a}}$ Fase da Pesquisa}

Nome:

1 - As sinopses abaixo contêm exemplos de phrasal verbs. Identifique-os, sublinhando-os.

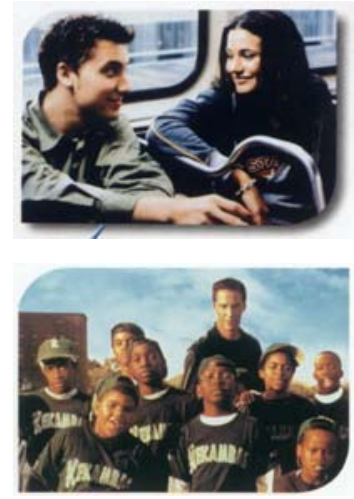

Kevin just met the girl of his dreams. But there's only one problem: he forgot to get her name and number. Now he and his friends will do anything to find her. And so Kevin becomes Chicago's poster boy for lost love. But do the forces of fate that brought them together in the beginning pull through a second time?

Conor O'Neill likes to bet on sports games, which makes him a dubious choice for a role model. However, his buddy won't help him pay off his debts unless he coaches a youth baseball team. All of a sudden, Conor is thrust into molding underprivileged kids in one of the toughest parts of Chicago.

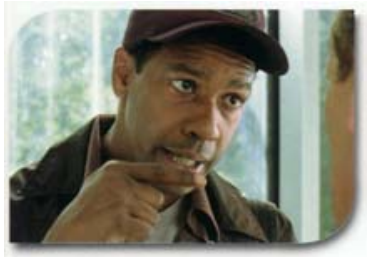

John Q. Archibald is an ordinary man who takes good care of his wife Denise and young son Michael. But when Michael falls seriously ill and needs an emergency heart transplant operation that John Q. can't afford and his health insurance won't cover, he vows to do whatever it will take to keep his son alive. With time and options running out, he takes the emergency room hostage. But many of the hostages need medical care themselves, and he faces off with a veteran police hostage negotiator and a police chief who wants to bring a swift end to the stand-off.

1- Por que você acha que são phrasal verbs ?

2- Escreva abaixo o significado dos phrasal verbs que você sublinhou:

\begin{tabular}{|l|l|}
\hline Phrasal Verb & Significado \\
\hline & \\
& \\
\hline
\end{tabular}

3 - Destaque alguns phrasal verbs e diga por que você acha que eles têm esse significado:

\begin{tabular}{|l|l|}
\hline Phrasal Verb & Justificativa \\
\hline & \\
\hline & \\
\hline & \\
\hline
\end{tabular}




\section{A AUTORA}

Adriana Mesquita Rigueira é mestre em Lingüística Aplicada ao Ensino/Aprendizado de Língua Inglesa pela Universidade Federal Fluminense, e está atualmente matriculada no programa de Estudos da Linguagem da PUC-Rio como doutoranda. No momento, leciona no PROLEM Programa de Línguas Estrangeiras e Materna, um projeto da Universidade Federal Fluminense. Interessa-se por estudos centrados no ensino e aprendizado de vocabulário em língua inglesa, com especial ênfase nos aspectos idiomáticos da língua, bem como por estudos focados em gêneros textuais e mídia digital. E-mail: rigueira@urbi.com.br. 